\title{
PATRIMONIO PLÁSTICO: DECISION-MAKING PROCESS, FOR THE RE-USE OF AN INDUSTRIAL ARCHITECTURE IN MONTEVIDEO
}

\section{Sabrina Sacco * and Maria Cerreta}

Department of Architecture (DiARC), University of Naples Federico II, via Toledo 402, 80134 Naples, Italy

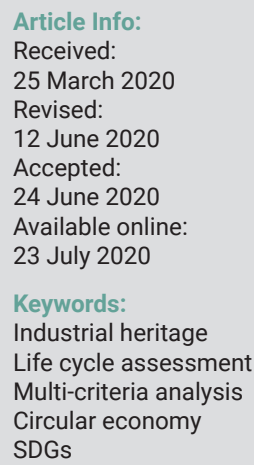

\begin{abstract}
This project is based on a research carried out between the Departments of Architecture in University Federico II in Naples and University of the Republic in Montevideo. The research is focused on the idea of re-using as a solution to trigger synergetic mechanisms among different entities and identities of the urbanscape. The core element of the study is Patrimonio Plástico, a decision-making process for the re-use of an industrial architecture, which deals with recycling waste and materials, such as plastic, containers, and abandoned spaces in the city. This multidisciplinary and multiscalar process translates into actions some targets of the Agenda 2030 SDGs, on a global scale, as well as the objectives expressed by different social groups at a local level, in order to identify the most suitable project, whose strategy has been assessed as economically, socially and environmentally sustainable.
\end{abstract}

\section{INTRODUCTION}

Patrimonio Plástico is decision-making process designed into a suburban area of Montevideo that shifts from the idea of transforming the waste into resource, and that one of giving new meaning to artefacts and places whose value has been underestimated.

The purpose of the research is to enhance the existing architectural heritage within a synergetic process that aims to convert the industrial building and the waste materials into a circular economy perpective.

Circular economy has been defined by the Ellen MacArthur Foundation (2017; 2019), as an autopoietic economy that radically transforms the standard production system based on a massive natural resources exploitation and the profit maximization - into a detailed revision of the entire chain involved in production.

The re-use of waste from the several production cycles becomes a crucial issue to be achieved in terms of economical, social and environmental sustainability criteria, as it requires cooperation, sense of community and a wide enhancement of the existing.

In this contribuition the concept of waste is expanded and the action of space recovery concerns a wide range of elements that can be divided into:

- Abandoned or partially used industrial buildings located in areas that are subject to urban transformation;

- Marginal communities against those ones living in the city centre;

\section{- Materials and objects considered "waste".}

The re-use of the industrial architecture in the city of Montevideo may lead to a way to implement the circular economy model, by dividing waste from environmental resources such as land use, energy and materials, and by creating a shared social value (Porter \& Kramer, 2006) thanks to its relationships with the social, cultural and economic history of the territory.

At this point supporting strategies that identify in this architecture vital elements for future transformations and see in the re-use strategy an urban solution to new economic, cultural and social values, becomes priority.

This contribution is organized as follows: the first section is dedicated to an accurate narration of the strong bond between the Aguada District and its industrial heritage, also mentioning the presentation of the industrial architecture as study subject; the second section presents the decision-making process developed through a multi-methodological approach (Fusco Girard et al., 2004) that combines different multicriteria methods (Ishizaka, 2013), chosen according to a site-specific selection, essential to identify the main stakeholders, whose projects and goals are expressed to make a comparison among the possible scenarios which can possible occur; the third section is dedicated to the results of this decision-making process and to an assessment of the economic, social and environmental sustainability of the scenario, able to mitigate the conflicts among the various stakeholders. 
The main purpose is to make explicit a methodological process which aims to define a strategy facing the existing conflicts and observing possible transformations from an economic, social and environmental sustainability perspective.

\section{THE CASE STUDY}

La Aguada, a neighbourhood not so far from the centre of Montevideo, belongs to those areas of the western coast of the city, like Arroyo Seco, Reducto, Bellavista and Capurro, that have faced till the first decade of the nineteenth century, the creation of several industrial plants leading the economy of the city, around which many working-class communities were born (Gilmet, 2001).

However, since 1920 the accelerated expansion of the city has led to an urbanization eastwards with consequent abandonment of the industrial headquarters such as La Aguada.

"A de-industrialization process that has left in the cities and in the entire country [...] hundreds of empty factories, abandoned by workers and deprived of the machines that populated them" (Massarente, 2019).

These industrial architectures, symbol of a prestigious past, appear today disused or underutilized (Chahinian Contreras, 2006). The relevant potential of these silent buildings is continuously undermined by urban planning that agree on their demolition against new residential towers, not interpreting the industrial identity of a district created to meet the demands of the machine and where there is no space for new residential communities at the moment, as they require infrastructure, services and entertainment.

Despite their widespread presence, the factories of Montevideo are not subject to relevant classification, except a list in the text "Patrimonio Industrial", written by the architect Lina Sanmartin (2009) as a proposal to adopt a future system-based information.

Among the factories of this area the Tsakos factory stands out (Figure 1). Particularly relevant for the relation established between port and city, it is the namesake of a Greek shipping company (Figure 2).
At the moment, the activity of Tsakos has considerably decreased, causing a significant reduction of staff, the underuse of available space and the need to be relocated for logistics reasons. Same story for many other factories in the country due to a process of de-industrialization which brought to a total or partial abandonment of the existing industrial buildings, causing their demolition sometimes.

Thanks to the studies carried out in the History of Architecture and Urbanism Department of FADU it was possible to trace the Factory Building Permits over the last century, the geometric reliefs and vintage photographs. The factory - built in 1910 - has a square plan divided into five naves with a pitched roof. Its massive size of about 6400 sq.m., occupies a whole lot in the neighbourhood.

The accuracy of the decorative details, the large bright windows and the size of the architectural complex highlights the popularity of the prestigious port in the early 1900s.

For the city of Montevideo, the the port plays a significant role as it is the engine of the economy of the country (Saldaña Fernández \& García de Zúñiga, 1939), which still grows occupying strips of land with its monumental walls of containers.

The extension of the port area and the changes made over the past decades show a poor analysis regarding the link between this neighborhood and the bay, which has led to economic growth in the last century.

The overcrowded port infrastructures and the intense production of waste by boats (Lozoya et al., 2015) become the pretext to think in terms of recycling and to participate to a broader discussion about the growth of the city.

In these terms, from a suburban area in continuous transformation, where the port economy makes the rules and where identity is compromised by profit interests, La Aguada is re-shaped through brand new circular economy practices that are slowly appearing in Uruguay, aiming at the promotion of tangible and intangible resources of the territory.

Uruguay has been promoting the "Programa de las oportunidades circulares" since 2018 in partnership with
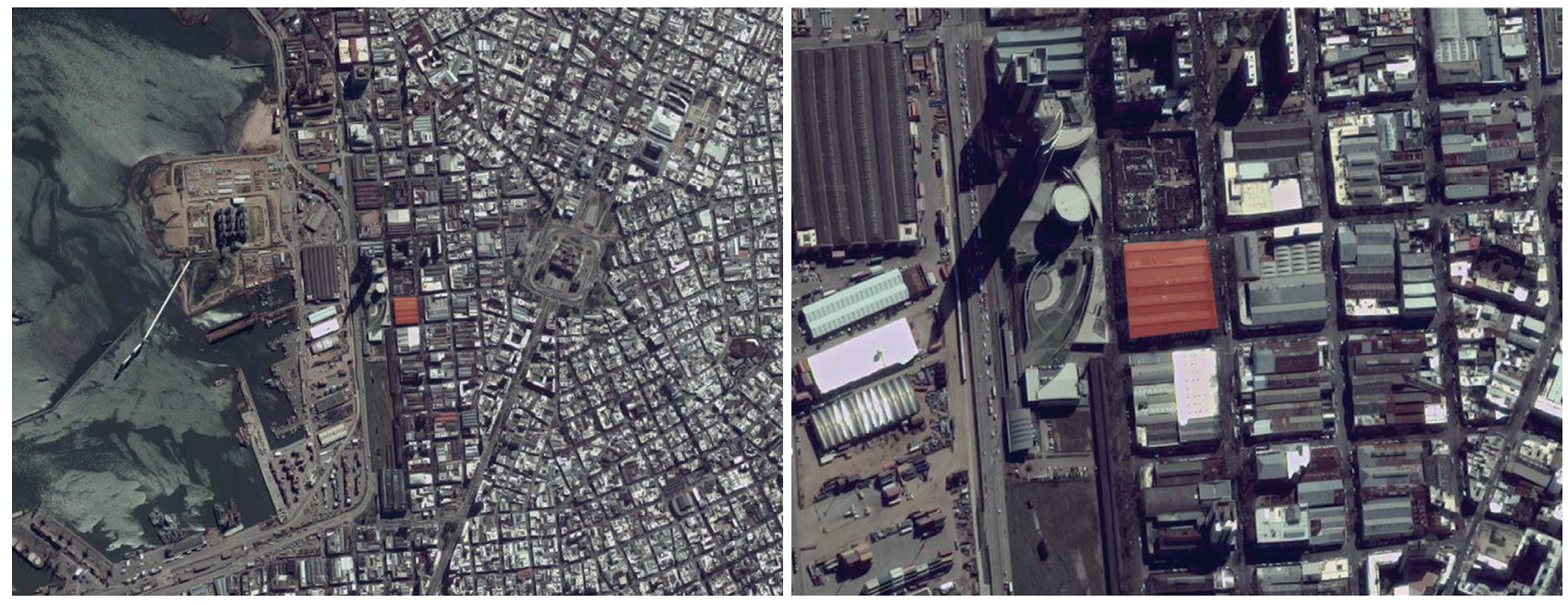

FIGURE 1: Aerial view of the Aguada neighborhood. 

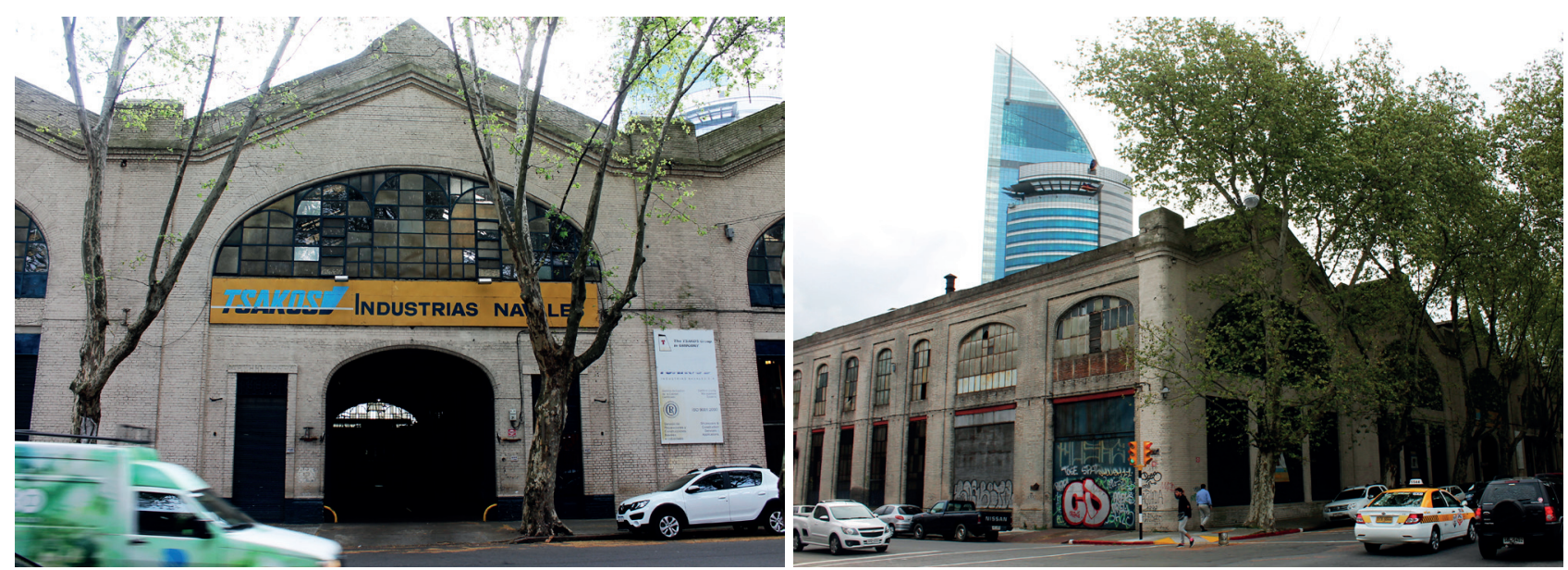

FIGURE 2: View of the Tsakos factory.

LATAM (Latin America's Circular Economy Forum) to launch production cycles in line with the principles of the circular economy, thus contributing to sustainable product development.

These practices highlight a growing sensitivity to recycling that finds its expression in re-use operations intended as a set of construction and/or re-use interventions of a building designed to respond to new conditions and new requirements (Douglas, 2006), but also as drivers of more comprehensive urban regeneration interventions with cultural, socio-economic and ecological objectives (Bullen \& Love, 2011; Cantell, 2005; Conejos, Langston, \& Smith, 2011; Yung \& Chan, 2012).

The centre of this discussion is the rich industrial heritage of Montevideo. Restoring dignity to these forgotten architectures means "collaborating with time in its previous aspects, grasping the spirit or modifying it, stretching it out, almost towards a longer future; means to discover under the stones the secret of the springs" (Yourcenar, 1951).

In recent years, adaptive re-use processes have been promoted in Montevideo, transforming the former industrial buildings into gastronomic and shopping areas, such as Mercado Ferrando and Sinergia Design, or into informal spaces dedicated to sports and cultural activities.

These operations become opportunities to finally "think of the city and the landscape as a matter of life cycles, whose parts can be recycled" (Massarente, 2019). and returned to the community with new meaning.

\section{METHODOLOGY}

According to the definition of re-use intended as a driver for urban regeneration, there is an urgent need to involve the local community into the process of space regeneration and to get to know its requirements, in order to get positive results for the definition of new intervention strategies.

The methodology adopted, with regards of what has been said previously, consists of three main phases: knowledge, processing and evaluation (Figure 3 ).

The knowledge phase includes all data collected from the study of the district thanks to bibliographical texts dedicated to the industrial growth of the city, the first production sites and zooms on the La Aguada neighbourhood (Altezor, Baracchini, 1971; Alvarez Lenzi, Arana \& Bocchiardo, 1986; Jacob, 1981; Mazzini A. Mazzini E. \& Salmentón, 2016; Wonsewer, Igleasias, Buchelli \& Faroppa, 1959), from the survey followed by photographs and interviews carried out in situ by companies, commercial activities, neighbourhood residents and leading figures of the social, economic and business urban scene.

The starting point of the research was an investigation of the elements featuring the identity of the district in La Aguada with its industrial heritage.

The critical study of this material, together with the inspections carried out, ensured the most completed vision of the artifact, with its history and its relationship with the surroundings.

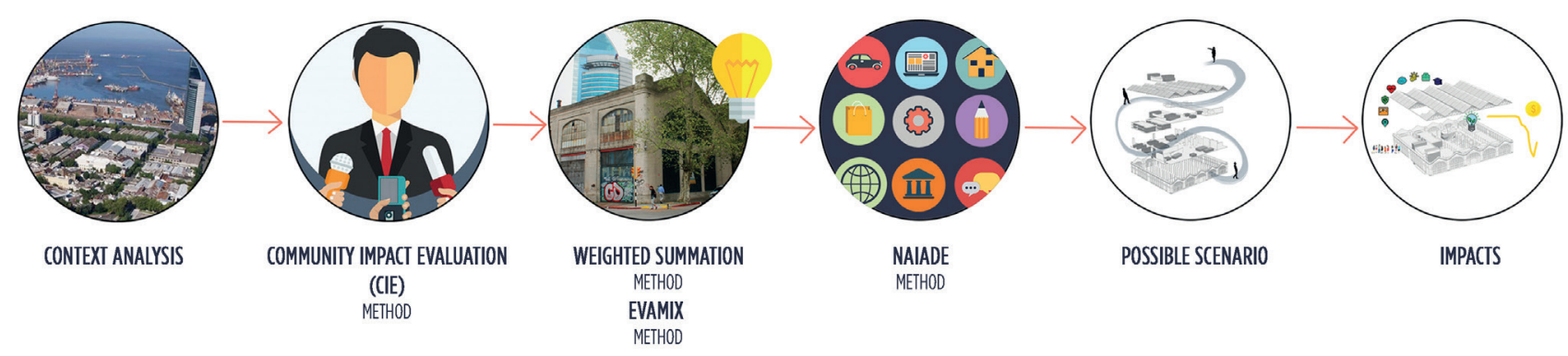

FIGURE 3: Scheme of the methodological process. 
The processing phase includes the analysis of these interviews through frequency analysis, equity analysis and the implementation of the Community Impact Evaluation (CIE) method (Lichfield, 1996; 2005). The interviews carried out in this phase are 14 and divided into three groups of stakeholders.

The first group of interviewees includes a large group of citizens able to provide an enlarged overview of the whole city, whilst the second group mostly focuses on the neighbourhood in terms of locals, and their business and commercial activities. The third group consists of important figures from the social, economic and business scene. Thanks to the Frequency analysis, it was possible to identify recurring concepts, words, phrases and define them as objectives to be pursued.

The most common objectives raised by the citizens, show the need of open spaces where spending free time and to be more safe. Indeed, the urban regeneration process is complex and polyhedric. Defining a complete and integrated vision of the actions to solve issues and improve economic, social and environmental conditions, requires strategies that involve stakeholders, each with its interests and objectives in the transformation processes (Cerreta et al., 2010).

It is necessary to define which are the social groups involved, i.e. the different categories of actors having a key role in the process:
Municipal administration;
Port Authority;
University institutions;
Local merchants;
Locals;
Local businesses;
Cultural enterprises;
Companies involved into initiatives for the re-use of pla- stic waste.

By defining the social groups, the new requests developed in the area for the promotion of the circular economy regarding the re-use of plastic waste, were taking into consideration. University institutions interested in the development of investigative research relating to the recycling of materials, were also involved. Starting from the collected data, five possible scenarios have been defined:

Scenario A: New residences;

Scenario B: Industrial hub and training centre;

Scenario C: New residences, an industrial hub, training

centre and cultural centre;

- Scenario D: Public space;

- Scenario E: Shopping Centre.

The five scenarios included a qualitative assessment regarding the equity analysis, and asked the social groups to express a rating going from "very good" to "very bad".

The application of the Community Impact Evaluation (CIE) (Lichfield, 1996;2005), a multicriteria and multiactor method that aims to define the convenience of complex projects based on the social preferences expressed by the various members of the community, allows comparing the general and specific objectives of the various social groups with the actions related to each proposed scenario.

The third and final evaluation phase deals with the analysis of the proposed scenarios starting from five indicators which are quality of life, environment, tourism, training and product innovation, chosen in order to be in line with a selection of the Sustainable Development Goals (SDGs), drawn up by the United Nations (2017) to address the challenges raised by climate change and to reduce any form of poverty or inequality, ensuring the long-term economic, environmental and social sustainability of human communities.

In this phase, the multicriteria methods of Weighted Summation and Evamix were implemented by the Definite 2.0 software (Herwijnen \& Janssen 1988), in order to make operative an assessment that combines the preferences of each social group with the hard data recognized during the knowledge phase.

For the selected indicators, measurement units were identified, specifying whether the objective was to increase the value or not, and finally, in respect of each scenario, indicating its new value.

The Weighted Summation allows to know which scenario shows the needs of social groups by establishing a hierarchical order among the five indicators already identified.

The Evamix method gradually changes the weight of each parameter giving prioriy to one and placing the others on the same level.

These results have been integrated with the construction of a conflicts dendrogram, structured by the NAIADE method (Munda, 1995), taking into account the equity analysis carried out during the elaboration phase, in order to know the possible coalitions between the stakeholders involved.

The conclusion of the different assessments carried out with different methodologies, leads to the common preferability of scenario C (Figure 4).

The selected scenario is the engine of a mixed functional program able to accept multiple identities of the neighbourhood. Once the preferable scenario has been obtained, the final step is the evaluation of its sustainability by the assessment of the environmental, economic and social impacts.

The environmental impact, carried out by a Life Cycle Assessment, aims to calculate the equivalent $\mathrm{CO}_{2}$ emissions produced by the plastic recovery process and its transformation by 3D printing which, as predicted by the scenario, takes place in the industrial architecture and makes a comparison between this, the incineration of the plastic material scenarios and use of virgin plastic.

The analysis of the economic impact, through financial investigation, considers construction costs, management costs and project revenues over a 20-year time.

Finally, the analysis of the social impact needs the comparison between the starting values of the indicators adopted, to analyze the context and the values created by the process. With regards to that, a reference is made to the indicators of Equitable and Sustainable Well-being (ESW) - a total of twelve indicators annually drown up by ISTAT. 
WEIGHTED SUMMATION METHOD

- LIFE QUALITY

- TRAINING

ENVIRONMENT

- TOURISM

PRODUCTIVE INNOVATION

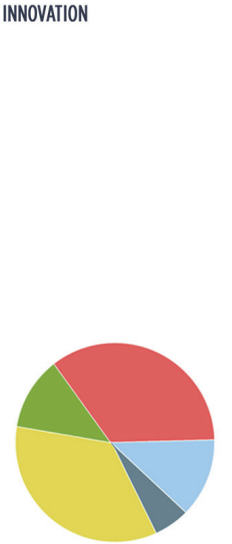

EVAMIX METHOD

- LIFE QUALITY

TRAINING

- ENVIRONMEN

- TOURISM

PRODUCTIVE INNOVATION

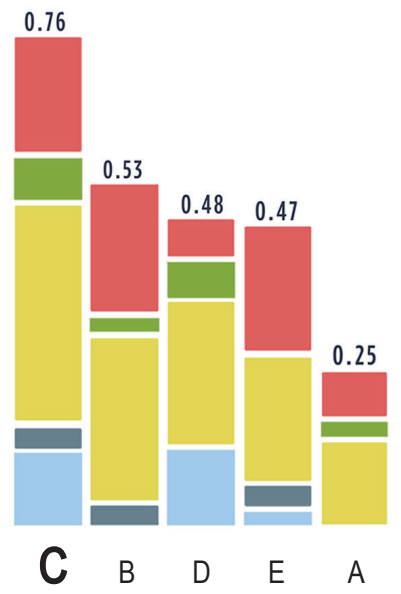

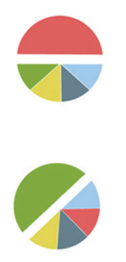

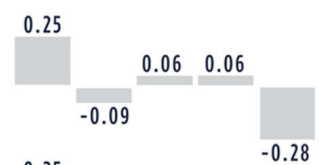

0.25

0.08

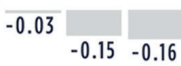

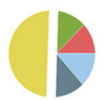

0.25

0.04

$-0.06$ $-0.22$
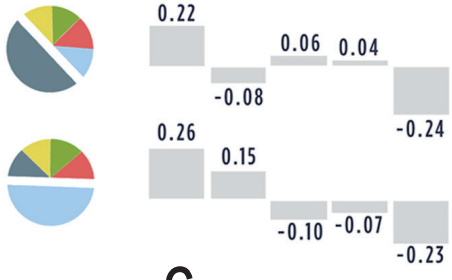

C B D E A

\section{NAIADE METHOD-DENDROGRAM OF COALITIONS}

\author{
G1 Municipality of Montevideo \\ G2 Port Authority \\ G3 Residents \\ G4 Automotive Companies \\ G5 Antel \\ G6 Ministry of Industry, Energy and Mining \\ G7 Ministry of Education and Culture \\ G8 Casa de los Vecinos \\ G9 Plastic waste recovery associations \\ G10 Multinationals \\ G11 Universidad de la Republica (UdelaR)
}

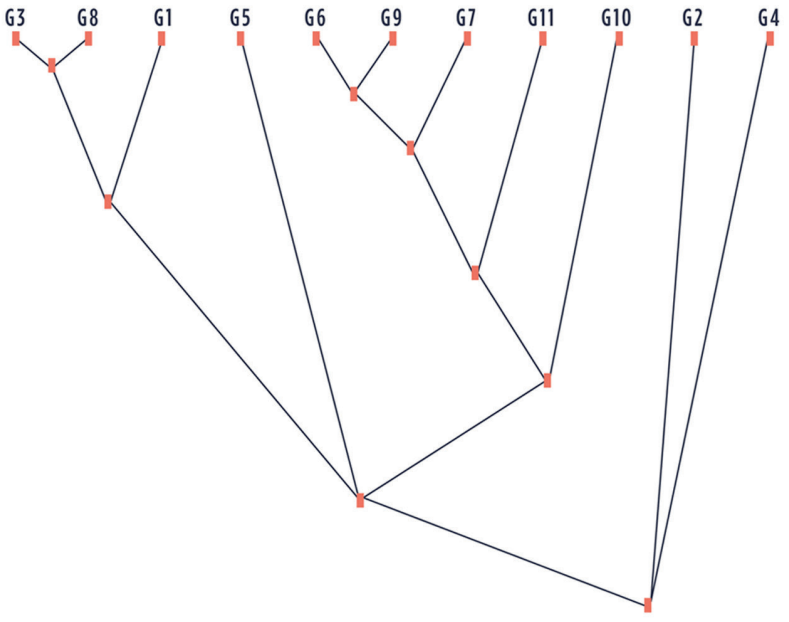

$\{\mathrm{GL}, \mathrm{G} 5, \mathrm{G} 8, \mathrm{G} 3, \mathrm{G1}, \mathrm{G} 10, \mathrm{G} 11, \mathrm{G} 7, \mathrm{G} 9, \mathrm{G} 6, \mathrm{G} 4\}$

\begin{tabular}{|c|c|c|}
\hline 0.8172 & C & 0.5 \\
\hline 0.8116 & B & 0.97 \\
\hline 0.7936 & D & 1.04 \\
\hline 0.7876 & A & 1.22 \\
\hline
\end{tabular}

0.7511

0.7151

0.6750

0.6396

FIGURE 4: Graphs of the results of the evaluation methods Weighted Summation, Evamix and Naiade.

\section{RESULTS AND DISCUSSION}

Both the Weight Summation method and the Evamix method lead to the same result, demonstrating how scenario $\mathrm{C}$ meets the requirements of the indicators chosen and the objectives expressed by the stakeholders.

The NAIADE method, applied to solve internal conflicts, leads to the same result by demonstrating the possibility by scenario $\mathrm{C}$ to combine divergent interests into a single project proposal.

The elaboration of stakeholders' map is useful to highlight how the functional program of this scenario responds to the needs of the various actors divided into three main categories: promoters, operators and users (Figure 5).

The result of the selected methodological process led to the definition of a democratic space that converts, according to the adaptive and creative re-use criteria, the current factory Tsakos into a cultural, training and production place (Figure 6).
The project proposal addresses the issue of what remains and "although it may seem paradoxical, such permanence is what allows to appreciate the changes" (Moneo, 1985). In this context, it is possible to think about the theme of recycling as a cultural process that transforms both the physical structure of the architectural object and the relationships that can be established with the material and immaterial context.

A new industrial 4.0 hub dedicated to recycling and processing PET plastic through the technology of the 3D printer, a training and scientific research centre, together with different leisure activities, gives back the space of the residual architecture to communities embracing new local virtuous processes (Figure 7).

The recycling of factory space happens in cooperation with the recycling of different materials (Figure 8).

First, the plastic, the symbol of the disposable use, is reconsidered according to the most recent technological advances as an architectural material, made to last. 


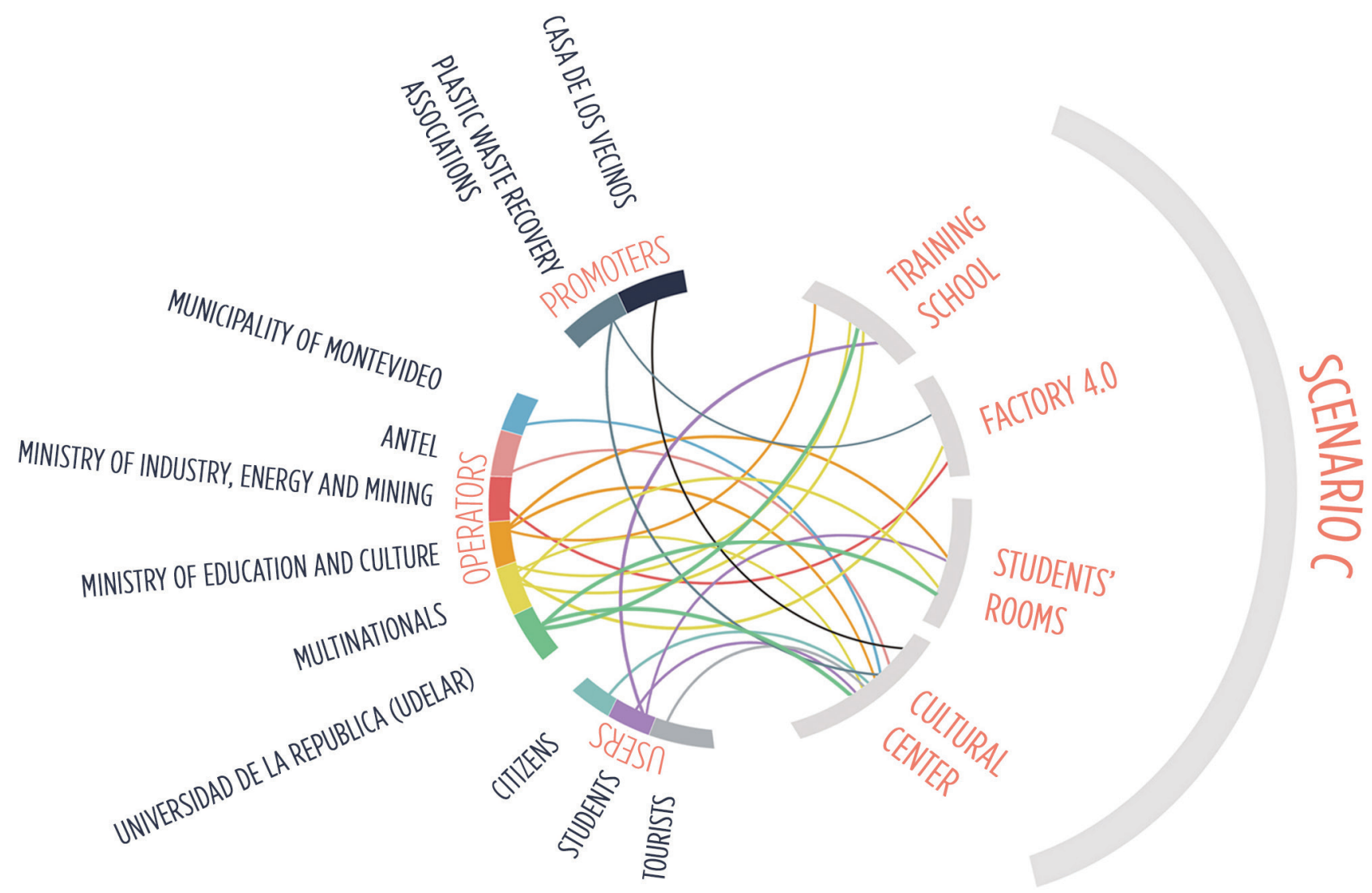

PANORAMIC TERRACE

TRAINING CENTER
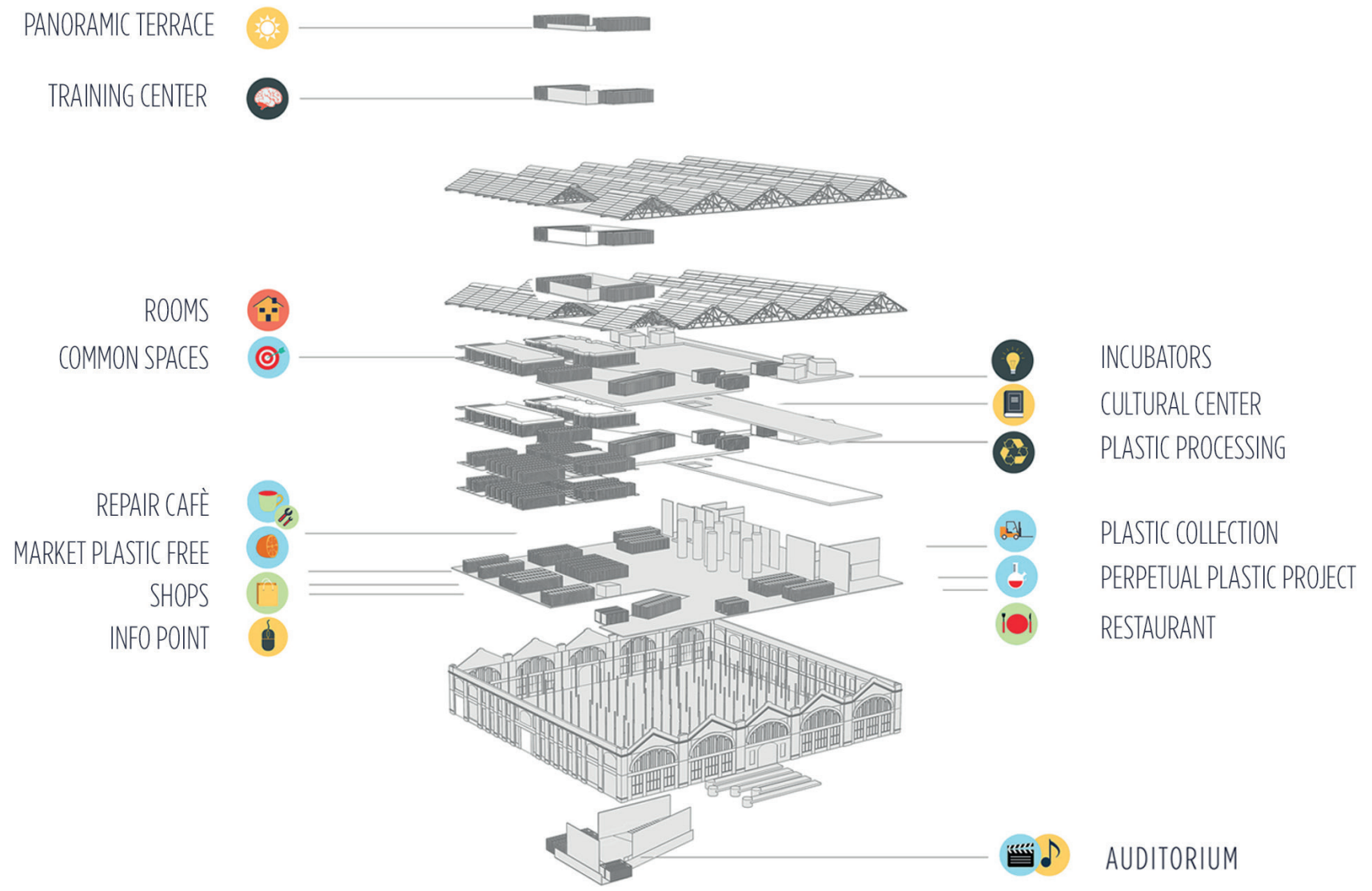

FIGURE 5: Stakeholders' map and a scheme indicating the functional program relating to scenario $\mathrm{C}$. 


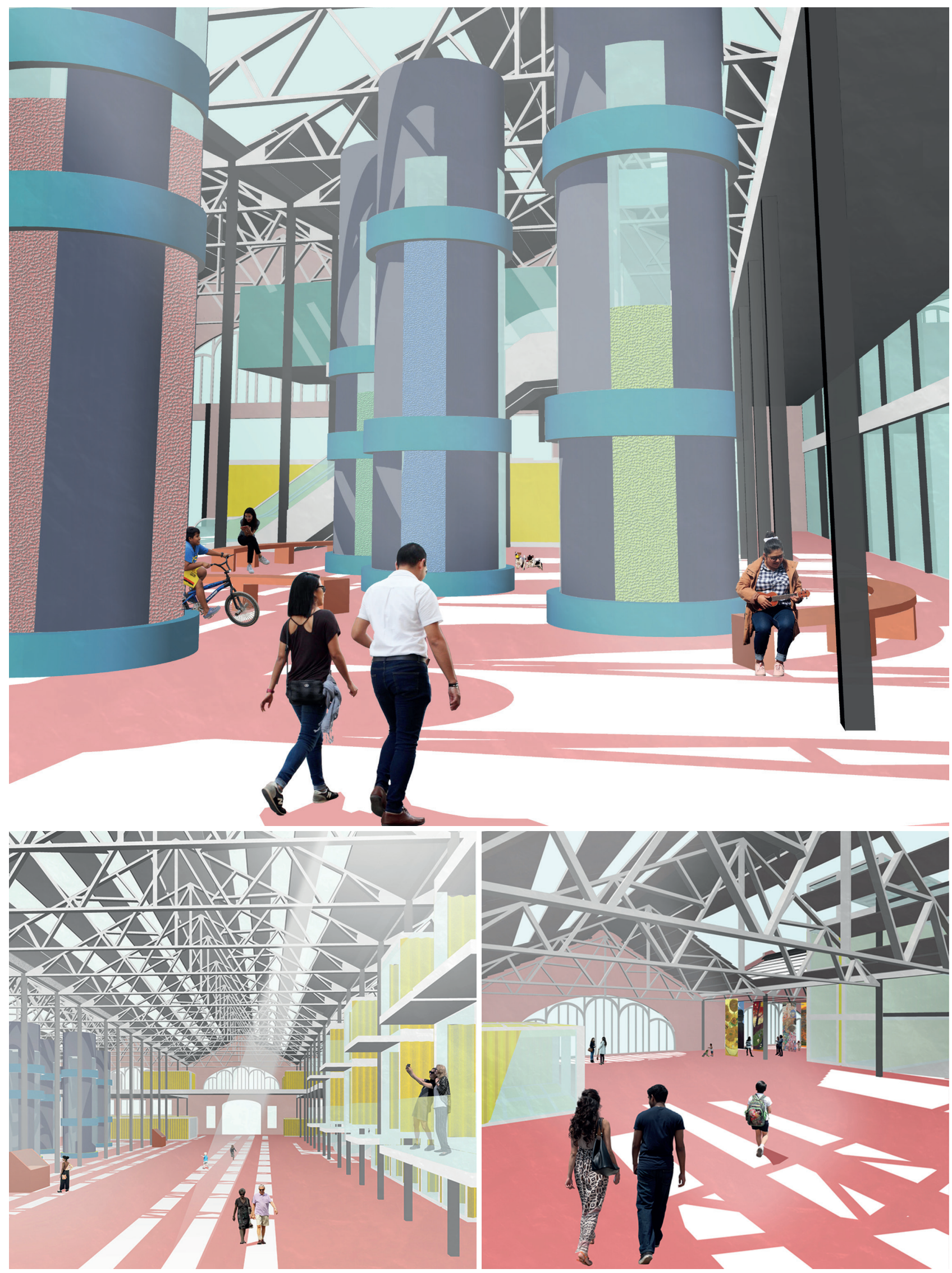

FIGURE 6: In order: View of the new silos, containing plastic shavings, around which the public space is organized; View of the covered square overlooked by the silos and containers used in the project; View of the meeting space overlooked by the training centre and the exhibition path. 
Through the collection and the processing, plastic becomes the primary material also for the production of spare parts for containers in accordance with the harbour enterprises demand or objects of common use commissioned by other users.

Even unused containers, coming from the near port, are re-used to define spaces, consolidate structural parts, articulate the space and the functions of the re-use project (Figure 9).

Reference is made to the international experience of many companies that assess innovative methods of waste materials recovery into a re-use in architectural design. Thus, the compressed plastic blocks, named Replast by the US company ByFusion, constitute the fifth stage of the auditorium on the ground floor; Miage sheets made of transparent and back-lit plastic by the Dixpari project, slide on rails in raw iron for the realization of the incubators of the research centre on the first floor; finally, the internal partitions of the residences for students, carried out inside containers, are made of structural walls achieved by the Mexican company Ecodom, whose thermal insulation is caused by the presence of solid compacted plastic waste (Figure 10).

Plastic is also an excuse to propose a model of social and creative enterprise that starts with the people to return to the people.

The factory space is open and permeable. On the ground floor, the interior space becomes space for the city, where people can stroll among shops, visit the "repair cafe", live experiences of the circular economy focused on plastic as the "perpetual plastic project" and enjoy performances and cultural events.

The "fast" experience of the ground floor is in contrast with a more intense experience on the upper floors, where you can visit the exhibition space of the cultural centre and the panoramic terrace.

All this is supported by continuous scientific research developed inside the incubator and the training centre, where students have accommodation and common areas.

The project, referring to the global goals for sustainable development of the United Nations, aims to build a sustainable community that fights against climate change, against all forms of inequality and any wastage.

The sustainability of this proposal is highlighted by the evaluation of the environmental, economic and social impacts, thus showing a reduction in emissions, a continuous gain in time and extraordinary positive effects in the community.

The Life Cycle Assessment considered the collection and the transport of PET, its transformation, its distribution and electricity and fuel to be used for the process. By comparing the proposed scenario with which demands the production of virgin PET and what provides the PET incineration at the end of the production cycle, it is possible to avoid $61 \mathrm{~kg}$ of $\mathrm{CO}_{2}$ equivalent every week.

The economic impact analysis, through financial analysis, considers the data obtained from the investment amounts in architectural projects in Uruguay, the main open-source work platforms and the average cost of life in Montevideo.

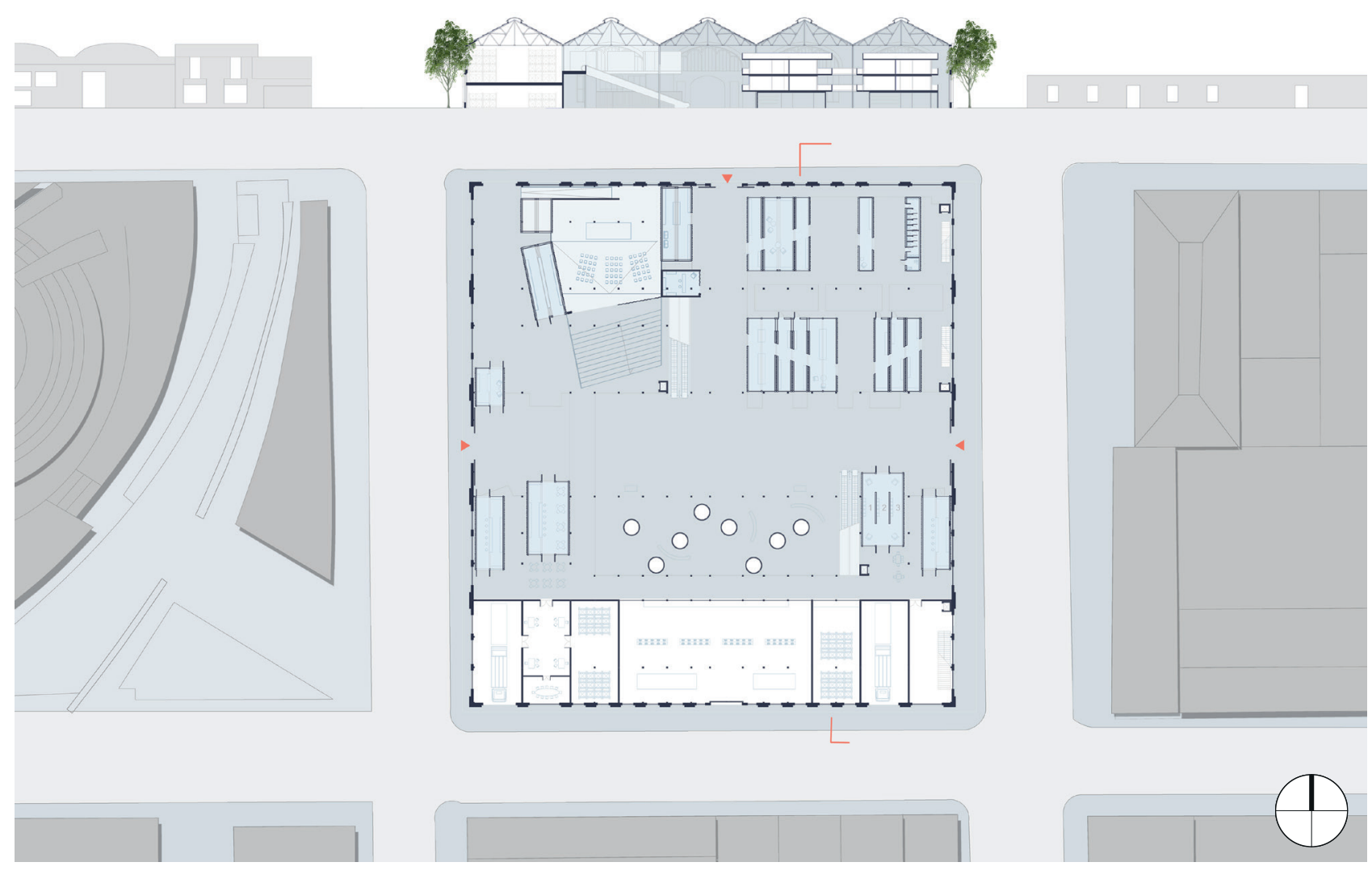

FIGURE 7: Ground floor plan highlighting the free covered space. 


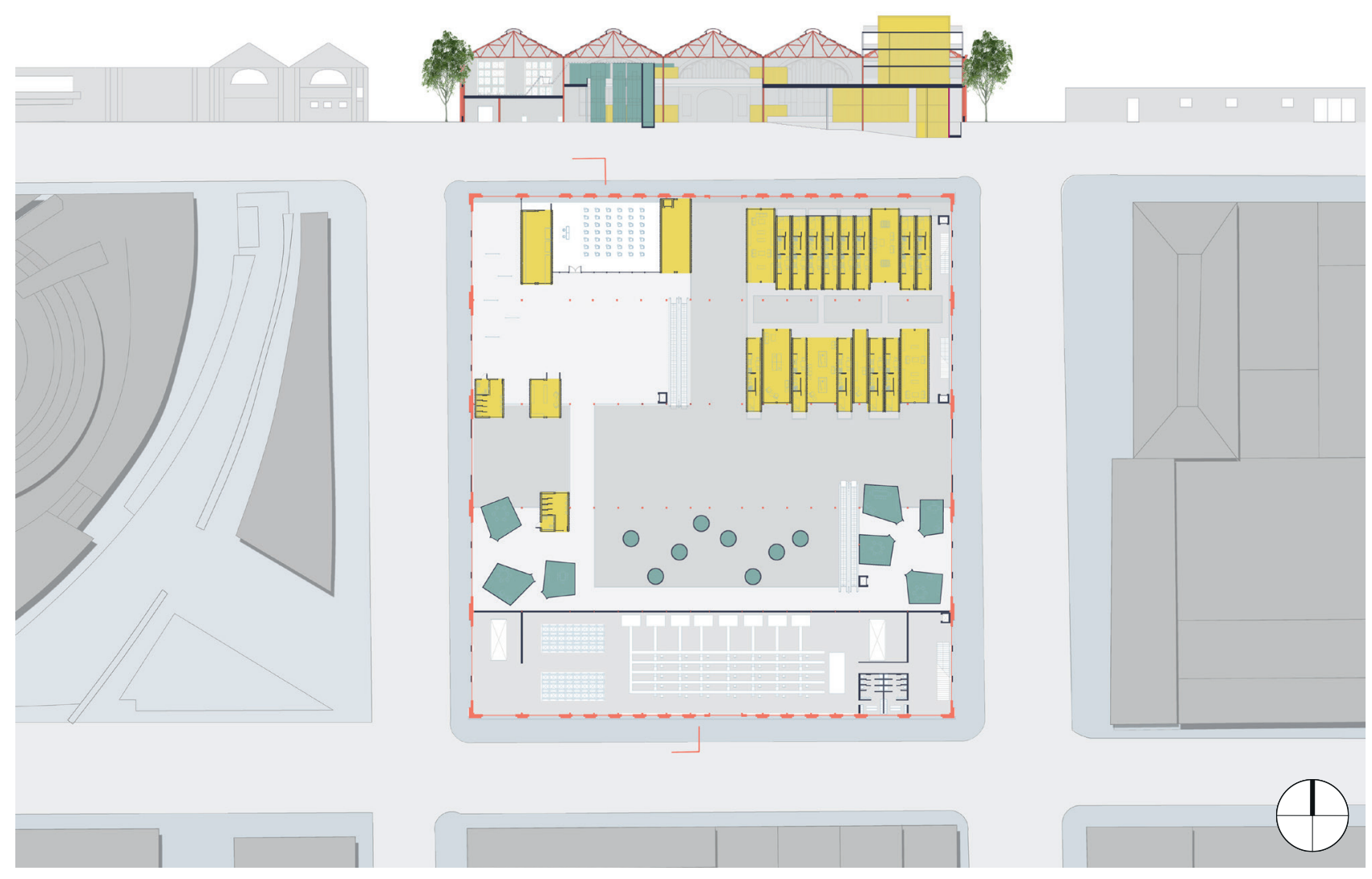

FIGURE 8: First floor plan highlighting the relationships between the different materials.

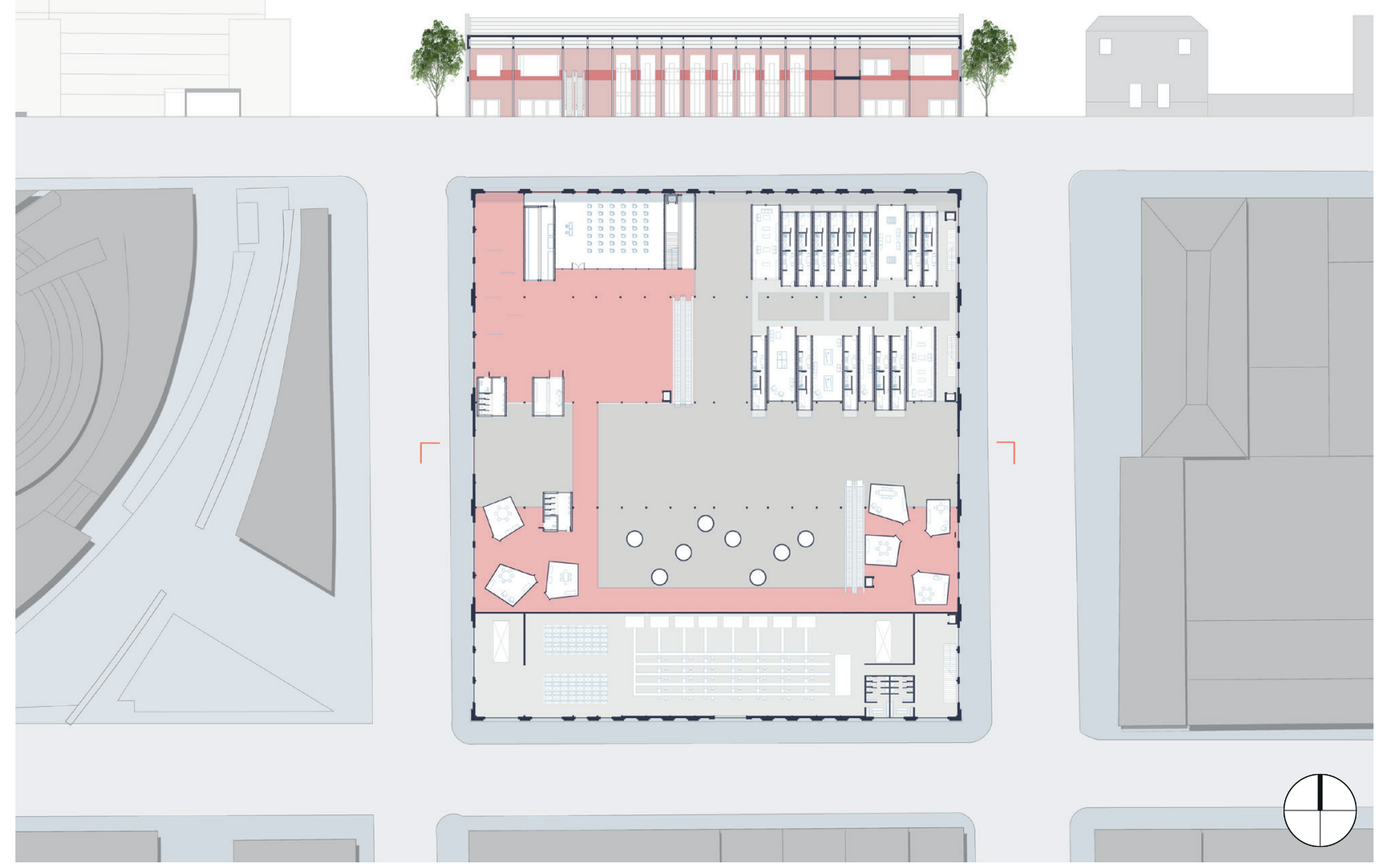

FIGURE 9: First floor plan highlighting the meeting space overlooked by the training centre, the exhibition path and the incubators. 
FIGURE 10: In order - 1) View of the fifth stage of the auditorium made by compressed plastic blocks named Replast by the US company ByFusion; 2) View of the walls of the incubators made by transparent and back-lit plastic sheets by the Dixpari project; 3) View of the internal partitions of the residences for students made by structural walls whose thermal insulation is caused by the presence of compacted plastic waste by the Mexican Company Ecodom.

From the difference of total net costs and total net revenues, it was obtained a high and positive Net Present Value (NPV) and an Internal Rate of Return (IRR) equal to $16 \%$. Therefore, the proposed project results sustainable and profitable in the reference period.

The project suggests a series of transformations as a response to social problems detected in the interviews and it has been tried to measure quantitatively indirectly through Equitable and Sustainable Well-being (ESW) indicators related to education and training, employment, economic well-being, environment, security, subjective well-being, landscape and cultural heritage, innovation, research and creativity.

By considering as targets to achieve, the increase of the numbers of enrolled students in training courses, the increase in the employment rate within the neighborhood, the organization of events and recreational activities, the increase in creative companies working in the area the increased of perception of safety thanks to the prolongation of district hours, the project proposal proves to know how to look carefully at the needs that raising from a careful analysis of the territory and how to propose a viable and sustainable alternative to the current condition.

\section{CONCLUSIONS}

The United Nations' SDGs have highlighted the importance of thinking about global development that promotes human well-being and preserves the environment.

The 17 goals relating to the environment, health, training, innovation, etc., offer a series of indicators able to read the real conditions of a context from which experts adopt and organize adequate intervention strategies.

The same line followed by the United Nations is found in the circular economy concept that defines a new economic system that, in its design, production, consumption, till the end-of-life destination of a product, knows how to seize every opportunity to limit the contribution of matter and energy and to minimize waste, paying attention to the realization of new social and territorial value (Ellen MacArthur Foundation, 2017; 2019).

The practice that best comply with these objectives is the act of re-using, a practice that aims at the conservation and protection of environmental resources such as soil, energy and materials but also at the cultural and social resources where the good, object of study, is made warning.

The proposed strategy identifies the decision-making process most suitable for analysing the study subject and oriented towards the adaptive re-use of the existing, in particular, of the industrial heritage.

The chosen methodological process was structured and composed in such a way that each method lead to the
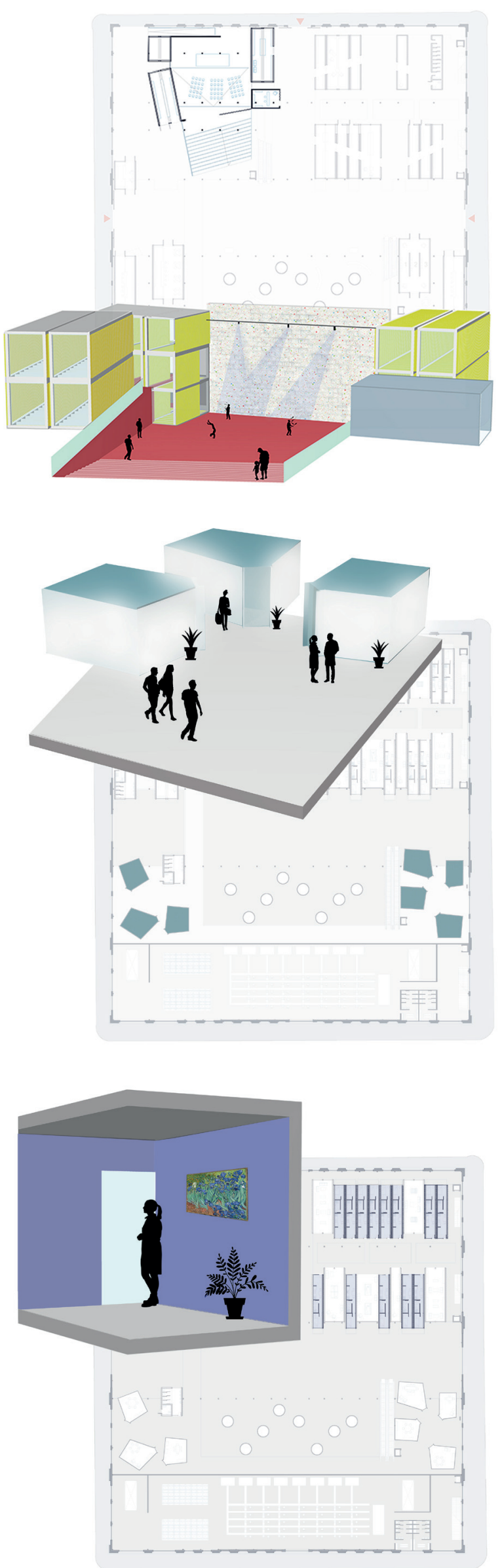
choice of the appropriate subsequent method according to the following general phases:

Data collection (bibliography, survey, site survey);

Definition of possible decision-making actors;

Submit interviews;

Interview analysis;

Definition of possible scenarios;

Comparison between possible scenarios and stakeholder preferences;

- Assessment of scenario multidimensional impacts.

This strategy combines global objectives and local authorities of the study subject and, at the same time, does not disregard the preferences of the community that lives and knows the neighbourhood and builds a process that leads to the definition of the preferable scenario. Therefore, the strong bond between the circular economy and community involved is fundamental for the re-use actions in the abandoned urban spaces.

For enhancing the tangible and intangible resources, in order to generate circular economy, it is necessary to consider the objective conditions of the territory but also the subjective preferences of those who inhabit that territory and the impacts that the project generates.

Based on the methodological process chosen, the evaluation of the consequences that re-use operations can have on the context, is central. Therefore, the final assessments of the impacts are crucial to bring out the ability of a re-use process to respond not only to the territorial issues but also to those promoted to improve sustainability at the global level, thus closing the framework of objectives established in the premise of the project.

This decision-making approach is effective for applying a circular economy perspective on the regeneration of existing assets. The aim of the research is not to present an absolute solution but to highlight the validity of a strategy applicable in cases of re-use of existing assets in a circular economy perspective. The research is proposed as an innovative experiment that, by stressing the importance of environmental and social issues, recognizes the value of those materials and those places of the city considered waste.

\section{AKNOWLEDGEMENTS}

The research presented in this paper has been developed in the Master degree thesis in Architecture of Sabrina Sacco, Department of Architecture (DiARC), University of Naples Federico II, tutors Prof. Paolo Giardiello and Prof. Maria Cerreta. The authors thank Dr. Marcello Casa and Rosario Tolomeo, Department of Industrial Engineering, University of Salerno, for their support and collaboration on the Life Cycle Assessment elaboration. The authors also thank tutor Prof. Marcelo Gualano, Prof. Anibal Parodi, Prof. Maria Jorge and Arch. Jorge Sierra, Department of Architecture, University of the Republic of Montevideo for their support during our stay in Uruguay.

\section{REFERENCES}

Altezor C., Baracchini H., (1971), Historia urbanistica y edilicia de la ciudad de Montevideo, Junta Departamental de Montevideo, Montevideo.
Alvarez Lenzi R., Arana M., Bocchiardo L., (1986), El Montevideo de la expanción (1860-1915), Ediciones de la Banda Oriental, Montevideo.

Baracchini H., Altezor C., (2010), Historia urbanística de la ciudad de Montevideo: desde sus origenes coloniales a nuestros dias, TRILCE, Montevideo.

Bullen, P.A.; Love, P.E.D. (2011). Adaptive reuse of heritage buildings. Struct. Surv.,29, pp. 411-421.

Cantell, S. (2005). The Adaptive Reuse of Historic Industrial Buildings: Regulation Barriers, Best Practices, and Case Studies, VA Polytechnic Institute and State University, Blacksburg, VA.

Cerreta M., Concilio G., Monno V., (2010). Making Strategies in Spatial Planning, Urban and Landscape perspectives, vol.9, pp. 381-404

Conejos, S.; Langston, C.; Smith, J. (2011). Improving the implementation of adaptive re-use strategies for historic buildings. In Proceedings of the Le Vie dei Mercanti S.A.V.E. HERITAGE: Safeguard of Architectural, Visual, Environmental Heritage, Naples, Italy.

Chahinian Contreras, F., (2006). Chimeneas sin humo, edificios with memory itinerary industrial por Montevideo. Montevideo, Uruguay: Fac. Arq. Diseño y Urbanismo.

Ellen MacArthur Foundation (2017), Cities in the circular economy: An initial exploration. https://www.ellenmacarthurfoundation.org/

Ellen MacArthur Foundation (2019), Circular Economy in Cities. https:// www.ellenmacarthurfoundation.org/

Fusco Girard L., Cerreta M., De Toro P., (2004), Integrated Planning and Integrated Evaluation - Theoretical References and Methodological Approaches, Beyond Benefit Cost Analysis, pp. 175-206.

Gilmet H., (2001). Urbanismo al eje El Plan de Ordenamiento Territorial y la Bahía de Montevideo, La ciudad construida urbanismo en América Latina, pp.344-366.

Herwijnen M. Van, Janssen R. (1988). "Definite”, in A.G. Locket, G. Islei (eds.), Improving Decision Making in Organizations, Springer, Berlin.

Ishizaka, A., (2013). Multi-Criteria Decision Analysis. Chichester, United Kingdom: John Wiley \& Sons.

Jacob R., (1981). Breve historia de la industria en Uruguay, Fundación de cultura universitaria, Montevideo.

Lichfield N., (1996). “Community Impact Evaluation”, UCL Press, London.

Lichfield, N. (2005). Community Impact Evaluation: Principles and Practice; Taylor \& Francis: London, UK, 2005.

Lozoya, JP et al., (2015, March). Management and research on plastic debris in Uruguayan Aquatic Systems: update and perspectives, Revista de Gestão Costeira Integrada / Journal of Integrated Coastal Zone Managemen, vol. 15, pp. 378-393.

Massarente, A. (2019). Stark, ready-made, recycling. Techniques of assembly and invention. Area 166 - re-use, 166, pp. 10-15.

Mazzini A., Mazzini E., Salmentón J., (2016). Cambios culturales, tipologias y tejidós urbanos, Montevideo 1907-1928, IHA Instituto de historia de la Arquitectura, Montevideo.

Moneo, R., (1999). The loneliness of the buildings and hallways writings. Issues around architecture. Turin, Italy: Allemandi.

Munda G. (1995). Multicriteria Evaluation in a Fuzzy Environ-ment: Theory and Applications in Ecological Economics, Physica-Verlag, Heidelberg.

Porter, M.E.; Kramer, M.R. (2006). Strategy and Society: The link between competitive advantage and corporate social responsibility. Harv. Bus. Rev.,84, pp. 78-92.

Saldaña Fernández, JM, García de Zúñiga, E., (1939). Historia del Puerto de Montevideo. Montevideo, Uruguay: Administración Nacional de puertos.

Sanmartin, L., (2009). Industrial Heritage. Montevideo, Uruguay: Dirección Nacional de Impresiones y publicaciones oficinales.

Schipper, L.E. and Langston, L. (2015). A Comparative Overview of Resilience Measurement Frameworks. Working Paper 422, Overseas Development Institute, London, UK.

United Nations (2017). Resolution adopted by the General Assembly on 6 July 2017, A/RES/71/313, https://unstats.un.org/sdgs/.

Wonsewer I., Igleasias S., Buchelli M., Faroppa L.A., (1959). Aspectos de la industrialización en el Uruguay, Publicaciones de la Universidad, Montevideo.

Yourcenar, M. (1951). Memoirs of Hadrian. Followed by notebooks of notes. Segrate, Italy: Einaudi.

Yung, E.H.K.; Chan, E.H.W. (2012). Implementation challenges to the adaptive re-use of heritage buildings: Towards the goals of sustainable, low carbon cities. Habitat Int., 36, pp. 352-361. 